$\begin{array}{ll} & \text { Etnográfica } \\ \text { etnográfica } & \text { Revista do Centro em Rede de Investigação em }\end{array}$

Antropologia

vol. 20 (2) | 2016

Vol. $20(2)$

\title{
Imaginando o bebê esperado: parentesco, raça e beleza no Rio de Janeiro
}

Imagining the expected baby: kinship, beauty and race in Rio de Janeiro

\section{Claudia Barcellos Rezende}

\section{(2) OpenEdition}

Journals

Edição electrónica

URL: https://journals.openedition.org/etnografica/4258

DOI: 10.4000/etnografica.4258

ISSN: 2182-2891

\section{Editora}

Centro em Rede de Investigação em Antropologia

\section{Edição impressa}

Data de publição: 1 junho 2016

Paginação: 231-249

ISSN: 0873-6561

\section{Refêrencia eletrónica}

Claudia Barcellos Rezende, «Imaginando o bebê esperado: parentesco, raça e beleza no Rio de Janeiro», Etnográfica [Online], vol. 20 (2) | 2016, posto online no dia 29 junho 2016, consultado o 10 fevereiro 2022. URL: http://journals.openedition.org/etnografica/4258 ; DOI: https://doi.org/10.4000/ etnografica. 4258

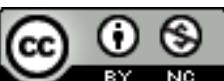

Etnográfica is licensed under a Creative Commons Attribution-NonCommercial 4.0 International License. 


\section{Imaginando o bebê esperado: parentesco, raça e beleza no Rio de Janeiro}

\section{Claudia Barcellos Rezende}

Neste artigo, discuto a gestação como momento de revalidação e atualização dos laços de parentesco. A partir de narrativas de gestantes de camadas médias no Rio de Janeiro, analiso o modo como imaginam a aparência física de seus bebês recorrendo aos traços físicos de suas famílias. Pensar no bebê esperado é uma instância de negociação com as identidades continuadas que vêm do passado, no momento em que se veem diante do futuro, projetando para o filho ou filha características, identidades e laços sociais. Neste processo, a associação entre parentesco e semelhança física é problematizada, na medida em que a continuidade física entre as gerações pode ou não ser desejada. Noções de beleza, raça e classe presentes na sociedade brasileira interferem no modo como o bebê esperado é imaginado. A continuidade entre as gerações que é desejada surge então menos como uma reprodução e sim como conexões "aperfeiçoadas", destituídas dos traços indesejados.

PALAVRAS-CHAVE: parentesco, gravidez, beleza, raça, camadas médias, Rio de Janeiro.

Imagining the expected baby: kinship, beauty and race in Rio de Janeiro In this article, I examine pregnancy as a moment of revalidation and actualization of kinship ties. Analyzing narratives of middle-class pregnant women in Rio de Janeiro, I discuss how they imagine the physical appearance of their expected babies resorting to family features. In thinking about the baby, they engage with the continued identities originated in their past, as they face the future projecting his/her characteristics, identities and social ties. In this process, the association between physical similarity and kinship is debated, since the physical continuity between generations may or may not be desired. In these narratives, notions of beauty, race and social class present in Brazilian society affect the way the expected baby is imagined. The desired continuity between generations figures less as a reproduction and more as perfected connections, in which the undesired traits disappear.

KEYWORDS: kinship, pregnancy, beauty, race, middle class, Rio de Janeiro.

REZENDE, Claudia Barcellos (cbrezende@bighost.com.br) - Departamento de Antropologia, Instituto de Ciências Sociais, Universidade do Estado do Rio de Janeiro, Brasil. 


\begin{abstract}
"É, eu já sonhei com o bebê algumas vezes. Cada hora ele vem de um jeito. Já veio até negro". [Roberta, grávida do primeiro filho]
\end{abstract}

"Family inheritance becomes an aesthetic lottery with winners and losers: those who come out with 'bad hair' or too dark skin” (Edmonds 2010: 147).

LAURA ESPERAVA UMA MENINA, QUE SE CHAMARIA MARIA. QUANDO indagada sobre como gostaria que fosse seu bebê, disse que queria que ela tivesse o cabelo farto de seu marido, já que o seu era ralo e fino. Ela dizia a ele: "Ai, tem que puxar seu cabelo!" Ela também gostaria que Maria tivesse o nariz dele, "porque o meu nariz, eu falo que é de batatinha. Então não, tem que ser o nariz dele, que é mais bonito. Mas tipo, os meus olhos, minha sobrancelha, eu gosto, assim, que lembra muito a família do meu pai”. Seu pai havia falecido quando ela era pequena e sua avó paterna foi muito presente na sua criação. Laura acrescentou então: "A gente não pode prever, né? A gente fica só imaginando, né? [...] A única coisa que a gente fica preocupada é se vai ter algum problema de saúde ou não". Para ela, estas preocupações eram inevitáveis depois de a mulher engravidar, receios de mãe. "Acho que aparência física... ah, se o cabelo, a boca, o nariz..., isso daí é um detalhe".

Ao longo de minha pesquisa com gestantes de camadas médias no Rio de Janeiro, a gravidez se apresenta como uma etapa em que as relações de parentesco estão em foco. ${ }^{1}$ Como apontam Duarte e Gomes (2008), a gestação do primeiro filho dá início à transformação da rede de parentesco, realçando a construção de vínculos diversos e a transmissão de experiências e circunstâncias. Acrescento que, neste momento, estes laços são reavaliados e atualizados, como na escolha do sobrenome do bebê, processo que pode afetar as relações com as decisões de não transmissão de um sobrenome (Rezende 2015). Esta reavaliação dos laços de parentesco também surge nas narrativas sobre a aparência esperada e desejada para o bebê, meu objeto de análise neste artigo.

Parto de uma perspectiva do parentesco como relações em processo de criação/revisão/transformação. Ao contrário da visão predominante na antropologia estrutural-funcionalista que o tratava como um sistema de vínculos que organizava os "fatos naturais" da procriação em unidades de relação bem definidas (Radcliffe-Brown 2013; Holy 1996), nas últimas décadas esta abordagem passou a ser questionada como um reflexo de conceitos nativos

1 Uma primeira versão deste artigo foi apresentada no XII Congresso Luso-Afro-Brasileiro, em fevereiro de 2015, em Lisboa, e agradeço os comentários de Susana de Matos Viegas, João de Pina-Cabral e Cecilia McCallum. 
euroamericanos de parentesco (Schneider 1980; Strathern 1992). A ideia de "fatos naturais" veio a ser tomada como fonte de interpretações e significados muito distintos, aliados frequentemente a outros elementos como base destas relações. Com isso, o parentesco vem sendo considerado um conjunto variado de símbolos e formas de conexão, que se constitui de modo dinâmico, processual e intersubjetivo (Carsten 2000a; Sahlins 2011; Schneider 1980). Ainda que exista, no universo pesquisado, a ideia do compartilhamento de substâncias como base para os vínculos de parentesco, vejo-a, como propõe Viegas, enquanto uma "natureza historicizada": "um processo histórico que valoriza a criação de relações em detrimento da conformação prévia dos fatos" (2007: 137). Assim, nas narrativas das gestantes, o convívio cotidiano, o apoio ofertado, a troca afetiva tornam-se elementos tão importantes para constituir e manter o laço de parentesco quanto compartilhar substâncias.

Se, no Brasil, a abordagem do parentesco como processos de construção/manutenção de relações tem sido mais frequente no contexto ameríndio (Gow 1997; Viegas 2007; Vilaça 2002), ela aparece menos em estudos das camadas médias urbanas. ${ }^{2}$ Peixoto e Cicchelli (2000) comentam como, a partir da década de 1970, as pesquisas sobre família no Brasil elaboraram tipos distintos de "família", tendo como referência a família nuclear, buscando assim caracterizar a vida familiar nos diferentes segmentos sociais ou setores produtivos e tratando-a como instituição social e como um valor. Fonseca acrescenta que não apenas em estudos brasileiros, mas também nos britânicos, as estruturas familiares aparecem reificadas e atuantes sobre os membros individuais, revelando também uma análise voltada para o self que, "dominada pela ideologia individualista, pensa a coletividade em termos de suporte ou entrave à realização pessoal" (2007: 9). No final dos anos 90, com os questionamentos feministas, pós-coloniais, dos movimentos gay e as novas tecnologias reprodutivas, vimos um retorno de estudos sobre família e parentesco, buscando desnaturalizar modelos eurocêntricos de reprodução e abrir espaço para outros idiomas de conexão (Fonseca 2007).

Neste artigo, argumento que os laços com os pais, avós e irmãos são continuamente atualizados e revisados, ganhando diferentes "pesos ontológicos" (Pina-Cabral 2010) em momentos de vida distintos. Considero a gravidez do primeiro filho uma destas situações em que os futuros pais lidam com suas "identidades continuadas", nos termos de Pina-Cabral. São formas de lidar com o passado que fazem parte de um processo de "copresença na constituição individual" (2013: 76), ligando as pessoas àqueles que vieram antes delas

2 Ver os trabalhos de Pina-Cabral (2010, 2013) e McCallum e Bustamante (2012) na Bahia, ambos em segmentos populares, respectivamente no Baixo Sul e em Salvador. Os estudos sobre as novas tecnologias reprodutivas (Fonseca 2004; Chazan 2007; Luna 2002) têm sido um caminho importante para propor formas distintas de construir o parentesco. 
e constituindo assim o núcleo de seus afetos. Pensar no bebê esperado é uma destas instâncias de negociação, por parte do casal, de suas identidades continuadas no momento em que se veem diante do futuro, projetando para ele ou ela características, identidades e laços sociais. Neste processo, constroem também o laço com o bebê para além de vínculos biológicos: através da escolha do nome e sobrenome, da sua percepção como pessoa com gostos e da especulação em torno de sua aparência física.

Neste último caso, imaginar a aparência física do bebê gestado torna-se um exercício de reflexão sobre as várias combinações possíveis de traços físicos, como sugerem os trechos das entrevistas de Roberta e Laura acima. Estes aspectos físicos são sempre remetidos às famílias. Porém, na medida em que estas combinações possíveis desenham fenótipos raciais distintos, desigualmente valorizados na sociedade brasileira, as gestantes expressavam sempre preferências e antipatias. Estes traços remetiam não apenas às identidades continuadas, mas igualmente a um posicionamento social almejado - em termos de classe social, raça ou etnicidade, articulado também a um ideal de beleza. Assim, a continuidade com as gerações anteriores era sempre imaginada, mas colocava-se como distinta, recebendo acentuações diversas. Portanto, busco problematizar a relação entre semelhança física e descendência, como outros autores (Cannell 201 1; Carsten 2000b; Cussins 1998; Nordqvist 2010), mostrando que as distinções de classe social, raça e etnicidade presentes na sociedade brasileira são mobilizadas juntamente com os pesos ontológicos dos laços de parentesco no processo de construir vínculos para o bebê.

Neste estudo, baseio-me em dados de uma pesquisa de campo realizada com um grupo de gestantes na zona sul do Rio de Janeiro e em 17 entrevistas conduzidas com mulheres que esperavam seus primeiros filhos. ${ }^{3}$ As mulheres entrevistadas foram selecionadas pelo método "bola de neve", levando em conta como critérios de escolha a primeira gestação, o corte etário, a situação civil, a escolaridade e a ocupação. Em ambas as situações de pesquisa, as mulheres tinham idades entre 28 e 35 anos, eram casadas e se consideravam parte dos segmentos médios, tanto em função de seus estudos universitários quanto de suas profissões. No entanto, para algumas, esta situação refletia uma trajetória de mobilidade social que as diferenciava de seus pais, cuja escolaridade não chegava à universidade. Metade das mulheres moravam em bairros distantes do centro da cidade, marcados por maior heterogeneidade socioeconômica, e as outras residiam em bairros de camadas médias na zona sul da cidade. Dentre as entrevistadas, cinco eram negras, havendo quatro delas que valorizavam suas identidades negras. Havia também uma diversidade de pertencimentos

3 Os dados analisados aqui resultam da pesquisa "Pertencimento e parentesco na gravidez", apoiada pelo Programa Pro-Ciência da UERJ, pelo CNPq (Bolsa de Produtividade) e pela Capes (Bolsa Estágio Sênior). Priscilla Silva, Thales Moraes e Bruno Hammes participaram como assistentes de pesquisa. 
religiosos: cinco evangélicas, uma messiânica, uma do candomblé, duas cujas mães eram judias, as restantes católicas, com graus diversos de adesão e prática.

As entrevistas indagavam sobre a experiência da gravidez - seu início, desenvolvimento e a antecipação do parto - bem como o modo como o marido, família e amigos se faziam presentes naquele momento. A maioria das mulheres estudadas morava perto de seus pais, quase todas em residência própria que passava por reforma para a chegada do bebê. Elas tinham contato diário com suas famílias - pais, irmãos, tios e avós - e consideravam estas relações próximas. Os sogros também eram considerados presentes, embora a relação com eles fosse com frequência marcada por diferenças de valores e práticas que podiam produzir tensões e atritos.

Nas seções seguintes, discuto através da literatura antropológica a relação entre parentesco e semelhança física e como a raça vem assumindo significados distintos na sociedade brasileira. Em seguida, apresento como as gestantes falam da gravidez como um estágio da maternidade, para então mostrar três narrativas específicas em torno da aparência imaginada do bebê. Ao final, articulo a análise destas narrativas às questões teóricas apontadas no início do artigo.

\section{PARENTESCO, DESCENDÊNCIA E RAÇA}

Nas sociedades ocidentais, a ideia de que o parentesco pode se constituir a partir do compartilhamento de elementos biológicos é historicamente construída, como mostram Johnson et al. (2013). Esta noção ganhou força na Europa a partir do século XV, quando o sangue passou a ser considerado um elemento que forma uma linhagem, uma raça, e transmite qualidades físicas e morais (Delille 2013). Naquela época, a transmissão de características era vista como acontecendo fundamentalmente de pai para filho, sendo a mulher tomada como um instrumento mediador do sangue paterno (Sabean 2013). Somente no início do século XX, com a divulgação das leis de Mendel, as qualidades físicas vieram a ser pensadas como vindo de ambas as famílias paterna e materna, mantendo-se, contudo, visões divergentes desta concepção (ver Essner 2013). Assim como o sangue, a semelhança física tornou-se um símbolo das relações de parentesco por seus aspectos involuntário e inalterável (Holy 1996: 20).

Ao contrário do sangue, porém, a semelhança física é frequentemente tomada como um modo de visualizar conexões (Cannell 201 l; Carsten 2000b; Cussins 1998; Nordqvist 2010). Nordqvist comenta que "quando um bebê nasce, seu corpo é visto como constituindo um laço de identidade social entre ele/a e sua família" (2010: 1132; minha tradução). Neste sentido, a semelhança física é comumente entendida como uma forma de continuidade das relações de família e de identidade compartilhada. 
Contudo, esta associação vem a ser problemática quando, por exemplo, os laços de parentesco se constituem por meio da adoção ou através de novas tecnologias reprodutivas. No estudo de Carsten (2000b) em torno das reunióes sobre adoção na Escócia, a aparência física é um elemento que diferencia o sujeito dos pais. $\mathrm{O}$ fato de pessoas adotadas buscarem informação ou contato com seus pais biológicos parece ser movido pelo desejo de preencher certas lacunas em suas biografias, que incluem em alguns casos entender porque têm uma aparência física distinta da de seus pais. Porém, ainda que o encontro com os pais biológicos pudesse esclarecer a razão de certos traços físicos, mostrando assim uma conexão física com eles, "os laços afetivos não eram uma consequência necessária” (Carsten 2000b: 692; minha tradução).

Entre casais lésbicos que recorrem à inseminação artificial para conceber uma criança, a questão da semelhança física pode ser manipulada em contextos distintos, como Nordqvist (2010) argumenta. As mulheres estudadas por ela escolhem doadores com características físicas semelhantes a suas parceiras, de forma que seus filhos se pareçam com ambas as mães. Todo investimento é feito no sentido de criar uma semelhança que "exponha" as relações familiares (2010: 1136), diminuindo o significado da participação do doador. Quando alguma diferença aparece e os traços do doador se destacam, sua presença é reconhecida na criança e torna-se um lembrete da participação dele em sua concepção (2010: 1139).

Nas narrativas que analiso aqui, a ideia da semelhança física como indicativa de conexão está presente, mas torna-se complexa na medida em que as pessoas se veem inseridas em redes de parentes com traços físicos variados. O amplo espectro de fenótipos na sociedade brasileira sempre foi remetido à sua história de miscigenação entre os colonizadores portugueses, os escravos africanos e a população indígena nativa. Embora seja um fato histórico, é também uma construção ideológica que recebeu diversos significados ao longo da história do país e que contextualiza os valores distintos atribuídos à variação fenotípica de que trato neste artigo.

Até o início do século XX, a miscigenação racial era vista como problema que explicava o "atraso de civilização" da sociedade brasileira (Rodrigues 1983; Romero 1949). Esta lógica ajudou a sustentar a onda de imigração europeia branca na virada do século, na esperança de que o "branqueamento" da população ajudasse a "civilizá-la". Na década de 1920, esta visão problemática de mistura racial foi alterada fundamentalmente, através do trabalho de artistas modernistas e de intelectuais como Gilberto Freyre e Sérgio Buarque de Holanda. A miscigenação passou então a ser entendida em termos culturais e não raciais e de modo positivo (Freyre 1981; Holanda 1982), vindo a compor a ideologia que embasou a construção de uma identidade nacional singular durante o governo de Getúlio Vargas. A valorização dada por Freyre à mistura racial tinha como contraponto a segregação racial nos Estados Unidos, 
de forma que suas ideias sugeriam uma visão do Brasil enquanto "democracia racial", na qual o racismo aparentemente não estava presente.

Entretanto, a imagem de paraíso racial foi seriamente afetada pelos estudos produzidos pelo projeto UNESCO na década de 1950, que mostraram como os ex-escravos ainda se mantinham nos estratos sociais mais baixos (Fernandes 1965; Wagley 1952). Expunham-se assim desigualdades sociais drásticas que indicavam também a ação de práticas de discriminação. Se inicialmente a associação entre raça e pobreza foi pensada basicamente em termos de classe social, na década de 1970 sociólogos argumentaram que o preconceito racial explicava porque pessoas negras com a mesma escolaridade que brancas frequentemente deixavam de ser escolhidas na seleção para o mercado de trabalho (Hasenbalg 1979).

Uma das razões pelas quais o racismo no Brasil aparece de forma escamoteada tem a ver com os sentidos dados à raça na sociedade brasileira. Até recentemente, a raça estava basicamente associada ao fenótipo e não à origem, como na sociedade norte-americana (Nogueira 1985). O fenótipo incluía não apenas a cor da pele, mas também traços como a forma do nariz e da boca e o tipo de cabelo. De acordo com esta lógica, a classificação racial tornava-se muito fluida e contextual, de modo que uma pessoa poderia ser descrita por vários termos de cor dependendo do contexto e daqueles com quem ela estaria sendo comparada. "Moreno", categoria que tanto se aplica a uma pessoa branca com cabelos escuros como a uma pessoa com pele em tons marrons, era um dos termos preferidos, justamente por ser elástico e relacional. Já os extremos "branco" e "preto" eram evitados porque apontavam para uma situação de oposição social (Maggie 1992). Além disso, a brancura ainda estava associada aos estratos sociais mais altos, de modo que a mobilidade ascendente de uma pessoa negra tornava-se traduzida em sua nova classificação como pessoa "mais clara". De forma semelhante, brancos de segmentos baixos "enegreciam".

Recentemente, com o crescimento do ativismo negro, de um discurso afirmativo de identidade negra e de uma classe média negra, a categoria raça vem adquirindo um novo sentido. Agora a importância da ancestralidade vem ganhando força, ainda que persista o sentido de fenótipo, dando origem a problemas de classificação em situações onde há políticas afirmativas de redução de desigualdade racial (Fry 2005). Souza (2012) mostra ainda como, mesmo entre negros de camadas médias para quem a origem familiar é crucial, há a preocupação de que os filhos tenham também aparência de negros. Ou seja, o fenótipo mantém-se uma arena importante de significados simbólicos para a raça na sociedade brasileira.

Assim, este contexto, no qual a desigualdade racial é muito presente e associada a disparidades sociais, informa o modo como as gestantes entrevistadas pensavam na aparência dos bebês que esperavam. Mas estes significados mais amplos ganham valores e sentidos variados de acordo com o pertencimento a 
redes específicas de parentesco, com posições sociais e raciais ou étnicas particulares. Antes de analisar três narrativas sobre as aparências imaginadas, apresento brevemente o modo como as mulheres pensavam a gravidez já inserindo o bebê em uma relação de parentesco.

\section{AS GESTANTES COMO MÃES}

A gravidez era vista como um estágio inicial da maternidade, entre as mulheres entrevistadas. Para a maioria delas, engravidar havia sido planejado cuidadosamente. Havia sido, em geral, uma decisão do casal, tomada após alguns anos de união. A estabilidade financeira também era considerada importante e, embora alguns maridos quisessem esperar mais, as mulheres tinham empregos estáveis na época da pesquisa. Todas expressaram o desejo de ser mãe, mesmo que isto provocasse ansiedade em muitas delas (Rezende 2012).

A percepção de que, como gestantes, já eram mães foi explicitamente expressa por algumas entrevistadas e implícita no modo como todas elas se referiam ao bebê que esperavam. ${ }^{4}$ Primeiro, os bebês esperados eram alvo de vários cuidados dentro do corpo, tanto pelas mulheres como por especialistas médicos. O desenvolvimento e saúde do bebê deveriam ser acompanhados por profissionais através de consultas e exames. A maioria delas trocou de médico ao saber da gravidez, buscando um obstetra que fizesse parte de seu plano de saúde. Com isso, o acompanhamento pré-natal prescrevia consultas mensais, além de vários exames. As ultrassonografias eram presenciadas também pelos maridos, sempre que possível, e eram vistas não apenas como forma de acompanhar o desenvolvimento fetal, mas também como modo de ver e se relacionar com o bebê, tornando-se muitas vezes uma experiência agradável. ${ }^{5}$

Além das consultas médicas pré-natais, as gestantes falavam bastante das mudanças em suas rotinas em função das preocupações com a saúde do bebê, além da sua própria. Por exemplo, elas tentavam reduzir o estresse criado no trabalho porque era visto como prejudicial ao bebê. Muitas interromperam as atividades físicas que faziam antes de engravidar por medo de trazer riscos ao bebê. O consumo de certas substâncias, como bebidas alcoólicas, cigarros e remédios analgésicos, deveria ser evitado porque também afetavam o bebê. No grupo de gestantes, algumas mulheres desejavam ter parto natural, sem recurso à anestesia, que poderia ser danosa ao bebê, ainda que pudesse ser um alívio das dores do trabalho de parto. A maioria das mulheres falava destas mudanças como algo a ser feito pelos bebês, apesar da dificuldade de modificar hábitos já bem estabelecidos. Algumas comentavam que esta mudança era um sacrifício

4 Para outras percepções da relação entre gestante e feto, ver Ivry (2010) e Morgan (1997).

5 Ver Chazan (2007) e Taylor (1998) sobre a importância do elemento visual das ultrassonografias como forma de tornar o bebê "real". 
pela saúde dos bebês. Para outras, era o cuidado que toda mãe tem que ter com seu filho, revelando assim uma dimensão moral da maternidade.

Em segundo lugar, os bebês também exigiam espaço na casa e um enxoval composto de uma lista longa de itens, que exigia uma preparação cuidadosa e demorada. Em todas as entrevistas, aparecia o ideal de que o bebê tivesse um quarto só para si, com móveis, objetos e enxoval, frequentemente bordados à mão com seu nome pelas futuras avós. A maioria dos casais tinha suas residências passando por um processo de reforma para a chegada do bebê. Embora as mulheres ganhassem boa parte do enxoval e mobiliário de membros da família e amigos, algumas viajavam aos Estados Unidos para comprar roupas e carrinhos que seriam mais baratos e de melhor qualidade.

Um terceiro aspecto era a visão de que os bebês esperados já seriam pessoas com gostos específicos. ${ }^{6}$ Uma gestante disse que seu bebê não gostava quando ela deitava, pois ele se movia mais e dava "chutes" dentro da barriga. Outra entrevistada comentou que, quando seu marido falava com seu bebê, ele se mexia e isto era sinal de que ele gostava da sua voz. Assim os movimentos dos bebês no útero eram interpretados em termos de padrões de comportamento que, por sua vez, refletiam gostos e temperamentos. Um bebê que se mexesse muito era visto como agitado, possivelmente uma criança que iria "dar trabalho". O gênero aqui tornava-se um elemento importante da pessoa do bebê, reforçando padrões de masculinidade (ser mais agitado e enérgico) e feminilidade (ser mais calmo e quieto). Além disso, o fato de já terem nomes desde o quarto mês de gestação contribuía para sua percepção como pessoas (Rezende 2015). Desde então, eram frequentemente referidos por seu nome, não apenas pelas gestantes e seus maridos, como também pela família e amigos.

Por último, as gestantes muitas vezes falavam de seus bebês como "filhos" em diversas situações. Muitas comentavam como seu "filho" já tinha muitas roupas e presentes, outras falavam de suas mudanças de hábitos como uma forma de cuidado com a saúde do "filho". Em todas estas referências, as mulheres apareciam como mães já antes do nascimento dos bebês. Esta visão foi textualmente afirmada por Fernanda, na ocasião de seu aniversário. Quando a parabenizei e mencionei que era seu primeiro aniversário como mãe, ela me corrigiu e disse que era seu "primeiro aniversário como mãe da Carolina fora da barriga".

Assim, os bebês esperados eram objeto de muita atenção, tempo e dedicação durante a gestação. Este cuidado, que para algumas se tornava um sacrifício, era visto como parte da relação entre mãe e filho, já em processo durante a gestação, mesmo antes do nascimento do bebê. Este vínculo era também um

6 Ao contrário de outras sociedades, como na região andina do Equador estudada por Morgan (1997), em que as características físicas e morais do bebê só eram vistas como fluidas e se formavam após o nascimento. 
laço com gerações familiares anteriores, como mostro a seguir em três histórias distintas sobre como os bebês eram imaginados em termos de sua aparência física. Foram escolhidas por apresentarem de forma mais aguda e elaborada elementos que apareceram em vários depoimentos.

\section{Os olhos dos sonhos}

Os sonhos têm um papel importante na narrativa de Valéria sobre sua dificuldade de engravidar. Ela recontou vividamente um sonho que teve antes de ficar grávida, quando ainda buscava razões para sua dificuldade em conceber. No sonho, um estranho lhe entregava um bebê que era feito só de galhos secos. Ela chegava em casa, mostrava o bebê à mãe, que não sabia como ajudar. Então, "eu erguia a criança para os céus e dizia: 'Senhor, está nas tuas mãos! Se tu me destes, tu vai operar... vai operar o teu milagre'. E aí, quando eu abaixava a criança, eu via nascendo músculo, aparecendo os órgãos, músculos, pele, tudo". Depois, ao relembrar o sonho, ela interpretou que Deus the havia enviado uma mensagem de que Ele ia "operar um milagre" nela. Algum tempo depois, ela fez uma fertilização in vitro e engravidou de um menino. Ela também teve sonhos sobre como ele seria fisicamente: clarinho, como o pai, bochechudo e com cabelos louros e cacheados. Ela não lembrava como eram os olhos, mas disse: "Peço a Deus que seja igual ao do meu irmão e da minha cunhada, a irmã dele [do pai]. Porque é aquele castanho bem claro, que quando fica no sol, fica meio azulado esverdeado. Adoro os olhos dele! Do meu marido também é, mas do meu irmão e da minha cunhada é mais. Então eu imagino que ele vai ser assim, com esses olhinhos". Ela também gostaria que ele tivesse seu nariz pequeno e seu cabelo ondulado.

$\mathrm{Na}$ narrativa de Valéria, os sonhos se destacavam. Embora outras entrevistadas mencionassem sonhar com o bebê que esperavam, o primeiro sonho dela foi recontado de modo muito vívido, e também aparecia como um ponto de inflexão em sua história reprodutiva. Ambos os sonhos colaboravam para a forma como imaginava seu bebê, ainda que o primeiro tivesse acontecido antes da gravidez. O segundo sonho sugeria uma imagem angelical de bebê, apesar da ausência de imagens de anjos na religião evangélica de Valéria. Os dois sonhos eram cheios de elementos religiosos, revelando a importância da religião em sua vida. De fato, para ela, Deus havia sido responsável pelo "milagre" de sua gravidez, como seria também pela aparência do bebê. Embora tenha recorrido a uma técnica reprodutiva como a fertilização in vitro e mencionasse seu conhecimento de enfermagem ao comentar sua gestação e planos para o parto, era Deus quem parecia ter a última palavra.

Seu segundo sonho descrevia seu "filho" parecido com o pai, em termos da cor da pele e do tipo de cabelo. Ela buscou em seu irmão e na irmã de seu marido traços para complementar a aparência do bebê, especificamente a cor dos olhos. Embora nem ela nem seu marido tivessem olhos claros, Valéria 
achava possível que seu bebê "puxasse" esta característica de outros parentes - no caso, os irmãos do casal. O termo "puxar" se referia à circulação de coisas - traços, nomes - que conectam duas gerações em uma lógica de reciprocidade (Motta 2007). Nesta lógica, os bebês "puxam" nariz, olhos, cabelo, cor da pele de suas mães, pais, avós, tios, bisavós, tornando-se interligados através de sua aparência. Assim, Valéria imaginava seu "filho" com traços físicos que claramente faziam dele membro de duas redes de parentesco.

Contudo, ao imaginar o que seu bebê "puxaria" de cada família, Valéria selecionou aqueles traços que ela realmente "adorava" - a cor clara dos olhos de seu irmão e de sua cunhada. Ao fazê-lo, fez como a maioria das outras mulheres: escolheu as características físicas presentes em ambas as famílias de que ela gostava mais. Valéria destacou aspectos que não eram apenas objetos de desejo seu, mas eram também particularmente significativos em uma sociedade tão atenta ao fenótipo racial: cor da pele, tipo de cabelo, cor dos olhos, forma e tamanho do nariz. O bebê imaginado por Valéria aparecia próximo ao fenótipo europeu associado às camadas sociais mais altas. De fato, foi comum encontrar a preferência explícita por traços europeus entre outras gestantes com trajetórias socialmente ascendentes, que assim como Valéria tinham pais sem formação universitária. Neste sentido, em sua imaginação, seu bebê teria elementos físicos presentes nas duas famílias, tornando assim seu vínculo com elas visível, mas também seria um pouco diferente, do mesmo modo que ela se diferenciara de seus pais.

Entretanto, Valéria se referiu também a um ideal de maternidade na qual as mães deveriam cuidar e aceitar seus filhos, independentemente da aparência que tivessem. Em seu primeiro sonho, ela recebeu o bebê de galhos secos de um estranho e tomou como seu dever cuidar dele, ainda sem saber como fazer isso. Sua própria mãe, muito presente em várias partes de sua narrativa, também é consultada no sonho, reforçando ainda mais este modelo de maternidade. Com a bênção de Deus e seu cuidado materno, o ser frágil e estranho se tornaria um bebê forte, de carne e osso.

\section{"Um bebê bem feito"}

Quando conheci Marina, ela estava no último mês da gestação, esperando uma menina que se chamaria Sofia. Para ela, "não tem muito mistério... ela tem que ser branquinha, do cabelo preto e meio rolicinha como os [pais] são, mas eu quero muito que ela pareça portuguesa porque a minha família é toda portuguesa, e eu acho muito legal ter esses traços familiares". Mas, na última ultrassonografia, ela notou que o bebê tinha o queixo curto e disse: "Merda, puxou o queixo curto do Roberto". Marina tentava não pensar em questões de beleza - "é futilidade", disse ela -, mas não conseguia. Explicou que ela havia sido o primeiro bebê da família e ela sempre ouviu a história de como ela tinha sido um bebê bonito, nascido com quase dez meses de gestação, "um bebê muito 
bem feitinho". Quando sua mãe a olhou pela primeira vez, disse: "Nossa, como pode a gente ter feito um neném tão bonito!" Ela se questionava: "Eu não posso ser tão fútil, isso não é importante, racionalmente eu penso assim, mas outro dia eu entrei no site [da maternidade] para ver os nenéns e eu achei os nenéns horrorosos". No final, disse que reprimia sua preocupação com beleza pois o mais importante era a saúde do neném.

Marina apresentou o modo como imaginava seu bebê em termos muito factuais; não havia "mistério". Ao contrário das referências divinas e aos sonhos feitas por Valéria, Marina afirmava que, uma vez que ela e seu marido eram parecidos fisicamente, sua "filha" se assemelharia a eles. Ela também se referiu às imagens das ultrassonografias para acrescentar traços que "estavam" lá, como o queixo curto. Assim, a tecnologia fornecia elementos com os quais imaginar os bebês (Chazan 2007; Taylor 1998).

Mas, como ela falava de um bebê que ainda não tinha nascido, havia espaço para a expressão de desejos. Marina gostaria que Sofia parecesse portuguesa - pele clara, cabelo escuro e rolicinha - porque sua família toda vinha de Portugal. Aqui, sua ancestralidade era caracterizada em termos étnicos valorizados que ela desejava transmitir ao bebê. Além disso, sua narrativa se destacava das demais por relacionar sua história como bebê, recontada pelos pais, com a forma como ela imaginava que seria sua "filha". Marina conectava assim seus desejos para o bebê com a história familiar do seu nascimento - sendo a primeira neta, sendo um bebê bonito e "bem feito", explicitando a importância da continuidade familiar para ela.

Apesar do seu tom factual, havia também o elemento do acaso no processo de "puxar" traços de vários familiares, de forma que o resultado seria sempre imprevisível. Na narrativa de Marina, havia o queixo do marido que ela achava feio e que aparentemente seu bebê teria herdado. A questão com o queixo não estava em possíveis dimensões sociais - étnicas ou de classe - problemáticas. Feria basicamente o ideal de que o bebê herdasse o melhor de cada família, deixando de lado o pior. Quando uma criança "puxava" o melhor de cada lado, os pais teriam "feito" bem o bebê, ideia que só Marina expressou. Sua alusão à ação dos pais ao fazerem um bebê bonito ecoava sua ênfase na agência e autonomia pessoal em outros momentos da entrevista, como ao escolher apenas parte de um sobrenome composto que deveria "tradicionalmente" ser passado assim.

A imprevisibilidade em torno da aparência do bebê tornava-se uma dificuldade para Marina por causa de seu desejo de ter um bebê bonito. Como uma psicóloga social que abraçava questões feministas, Marina sentia-se muito ambivalente. Por um lado, via sua preocupação com beleza como "fútil" e tentava reprimi-la, pois recém-nascidos não precisam ser belos e sim saudáveis. Por outro lado, seu receio era tal que havia recentemente procurado fotos de bebês no site de uma maternidade. Aqui parece haver uma dimensão de gênero, 
pois outras gestantes que esperavam meninas também falaram da questão da beleza. Como Daniela disse sobre o bebê que esperava, ela não precisava se preocupar com sua aparência, pois ele era um menino e não seria problema se ele não fosse bonito. Esta preocupação com a beleza das meninas não tinha aqui uma relação com classe social, como apareceu no estudo de Edmonds (2012), pois tanto as mulheres com pais de camadas médias como aquelas de trajetória ascendente a expressavam. Mas a questão da beleza era ao mesmo tempo vista como fútil, egoísta, moralmente problemática, pois o que as mães gestantes deveriam realmente desejar era que seus bebês nascessem com saúde, como disse Laura no começo deste artigo.

\section{"Deus não dá tudo"}

Simone disse que ela tinha visto o rosto do bebê na última ultrassonografia. Tinha seu nariz de "batata" e a boca do marido, Fernando. Ela comentou: "Acho que ele vai ser amarelinho da estrela. Sararazinho, pretinho sararazinho. Fernando fala que vai botar ele no sol... [risos] Eu e Fernando a gente queria [que ele fosse pretinho], mas a gente sabe que não vai ser. Mas o Fernando fala que vai puxar a avó, o avô. Eu queria que ele fosse retinto. Mas, Deus num dá tudo, né? [risos] Mas eu acho que vou amar de qualquer forma assim. Clarinho, sendo pretinho, pouco pigmentado, muito pigmentado. Preto vai ser". Simone era uma socióloga muito falante e ativista do movimento negro no Rio de Janeiro. Sua narrativa sobre a gravidez era composta por várias outras narrativas sobre sua família - seu pai, um mulherengo charmoso do candomblé; sua mãe, uma bela mulher que, "como toda mulher negra" da época, trabalhou como empregada doméstica, cuidou dos filhos sozinha, estudou e conseguiu se formar em enfermagem para morrer de câncer antes dos cinquenta anos de idade; seu irmão distante, que nunca levou a vida a sério; seus dez tios e tias, todos criados por sua mãe e muito presentes em seu cotidiano. Ela contou a história de Fernando, também ativista negro, que nasceu da união entre um nordestino de pele clara e uma mulher negra e pobre, mas foi criado pela avó paterna, considerada sua mãe "branca". Sua mãe biológica era chamada pela avó de "macaca", morava em uma favela e teve outros dez filhos, de modo que Fernando tinha irmão "por toda a cidade". Simone e Fernando tinham uma relação conjugal estável, ao contrário dos pais dela que estavam se separando quando ela foi gerada, tanto que sua mãe tentou "tirá-la" e nem havia escolhido seu nome quando ela nasceu. Já seu bebê foi desejado por muito tempo e já tinha nome - um nome de origem africana que começava com a inicial do nome da mãe de Simone, para homenageá-la. Mas o tom de preto que ele teria permanecia um mistério.

A narrativa de Simone era distinta no modo como ela conseguia conectar suas expectativas sobre seu bebê a sua própria história, a do marido e de suas famílias. Ao longo de sua entrevista, a cor da pele era um elemento recorrente, 
como um traço que identificava várias pessoas como negras e que era passado de gerações anteriores aos seus descendentes. Era coerente então que ela escolhesse a cor da pele do bebê como objeto de elaboração em seu exercício de imaginação. Mais do que seu nariz de batata ou a boca de seu marido, seria a cor preta - bem retinta - que o colocaria claramente na sua rede de parentesco e na linhagem materna de seu marido. Como outras mulheres negras entrevistadas, a cor preta era desejada para o bebê como traço que o identificaria como negro, evidenciando não apenas uma origem africana mas também uma história familiar de muita "luta" na vida.

Contudo, Simone oscilava entre desejar esta cor de pele e saber que seu bebê não a teria. Como na história de Marina, ela também se referiu a imagens obtidas através de ultrassonografias, que a fizeram dizer que o bebê teria seu nariz e a boca de seu marido. Mas ao passo que a tecnologia pode "revelar" estes traços, a cor da pele só poderia ser imaginada e era vista como imprevisível: poderia ser muito escura, mas também clara, "amarelo", nas palavras de Simone. Cabia a Deus decidir, pensava ela, assim como Valéria.

Ao longo de sua narrativa, Deus e os orixás africanos eram muito presentes mas explicavam coisas distintas. Deus era responsável por aquilo que ela não sabia - porque ela demorou tanto para engravidar, a cor da pele de seu bebê e era visto como "não dando tudo". Seus orixás pareciam mais benevolentes e Simone atribuía a eles o apoio em diversos momentos de sua vida, como quando conseguiu comprar seu apartamento. Mas eles não foram invocados quando ela discutiu a cor da pele do bebê. Se a transmissão de traços físicos parecia ser determinada pelo divino, restava a eles a possibilidade de pôr a criança no sol, para fazê-lo mais escuro.

O significado da cor da pele do bebê também aparecia na possibilidade mencionada por Simone de que ela não o amaria, caso não tivesse a aparência desejada. Neste sentido, enquanto outras mulheres precisaram afirmar a importância de ter uma boa saúde, mais do que uma boa aparência, Simone foi a única que falou, ainda que em tom jocoso, sobre os limites de seu papel de mãe. De fato, sua história era cheia de mães que estavam muito distantes do modelo da mãe que se sacrifica pelos filhos (Mayblin 201 l): sua avó alcoólatra que proibiu sua mãe de estudar para que ela cuidasse dos irmãos, sua mãe que tentou interromper a gestação de Simone, a avó de Fernando que o tomou de sua mãe negra, que aparentemente durante anos havia deixado seu filho de lado. Sua narrativa revela assim pontos de tensão em torno de como as mulheres desempenham seu papel de mães: se pensam mais nelas - em seus próprios desejos, como ter o bebê com a aparência sonhada - ou nos filhos, amando-os independente de como nascem. 


\section{A CONTINUIDADE APERFEIÇOADA}

Laura, Valéria, Marina e Simone apresentaram suas próprias formas de imaginar os bebês que esperavam, com particularidades e semelhanças entre elas. Suas narrativas se distinguiam em termos do quão imprevisível seria a aparência do bebê e das características específicas que desejavam para eles. O modo de elaborar estas expectativas também era variado - com ajuda de sonhos, imagens de ultrassonografias e histórias familiares -, assim como era a maneira de lidar com o desconhecido - com referência a Deus, aos orixás ou como um mistério. Elas também tinham experiências familiares distintas, que em alguns casos se relacionavam a posições de classe ou pertencimentos étnicos ou raciais específicos.

Entretanto, há regularidades em todas as quatro, como nas outras gestantes pesquisadas, em torno do modo de imaginar o bebê. Quero destacar aqui duas ideias centrais nas narrativas analisadas, dialogando com alguns dos debates apresentados no início do artigo: o movimento de traçar continuidade entre as pessoas, e a busca de diferenciação entre as gerações via o que chamei de aperfeiçoamento.

Tomar o parentesco como processo implica em estar atento a todas as formas contínuas de estabelecer, atualizar, rever as relações que vinculam as pessoas dentro de uma rede de parentes. Assim, a gravidez é uma experiência que recebe significados culturais muito distintos, como mostram, por exemplo, os estudos de Morgan (1997) no Equador andino e de Ivry (2010) em Israel, onde os vínculos com o bebê só começam a ser estabelecidos após seu nascimento saudável. No universo que discuto aqui, o laço com o bebê durante a gestação era ativamente construído não apenas pelos cuidados da mulher como mãe que o via como "filho", mas também através de referências constantes a elementos que o ligavam ao pai, avós, tios, etc. Ter um nome e sobrenome escolhidos e uma aparência imaginada com traços "puxados" da família eram modos de construir o bebê como fazendo parte de uma rede de parentesco.

Este exercício de imaginação pode ser visto como um esforço de conectar gerações passadas e presentes de uma rede de parentesco a uma futura que estava por se iniciar. Neste sentido, inverte o movimento estudado por Cannell (2011) dos ingleses que buscavam suas genealogias. Cannell argumenta como o interesse em descobrir antepassados e fazer genealogias seria uma forma de construir vínculos com os mortos. Vejo o movimento das gestantes de imaginar as características do bebê esperado como um modo de projetar para o futuro laços com um ser ainda não nascido. Os traços imaginados para o bebê eram sempre características físicas que eram "puxadas" de suas famílias e das de seus maridos. Se a semelhança física pode ser considerada um modo de visualizar conexões entre as pessoas (Carsten 2000b; Cussins 1998; Nordqvist 2010), 
sua projeção parecia também criar continuidade entre o bebê, seus pais e suas redes de parentesco.

Contudo, neste processo de projetar vínculos, algumas pessoas da rede ganhavam mais ênfase do que outras. Pina-Cabral (2013) discute como as pessoas negociam suas identidades continuadas com aqueles que fizeram parte de sua constituição individual, como na escolha de um nome como sendo mais "verdadeiro" que outros (Pina-Cabral 2010). Estas escolhas revelam aquelas relações que têm mais significado ou presença que outras, tendo assim maior "peso ontológico". Na gravidez, as mulheres não apenas evocam seus passados, mas projetam esta evocação para o futuro, selecionando aqueles traços físicos familiares que gostariam de ver nos filhos. Assim, Marina queria que a filha se parecesse com a sua família portuguesa, de quem ela era tão próxima, achando feio o queixo da família de seu marido, com quem tinha muitas diferenças de opinião. Laura desejava para a filha a sobrancelha da família de seu pai, que havia falecido quando ela era pequena e cuja mãe havia sido muito presente em sua criação. De fato, quando elas desejavam que seus bebês "puxassem" o melhor de cada família, havia ali uma visão particular da continuidade familiar - uma que seria aperfeiçoada, resultando na criança uma combinação de feições distinta e única.

Esta continuidade aperfeiçoada revela, portanto, uma dimensão estética significativa. A preocupação com a beleza, em particular dos bebês meninas, foi constante nas narrativas e remete a construções culturais específicas do que seja belo ou, ao contrário, feio. Gomes (2011) argumenta que a beleza não se refere às qualidades dos objetos, mas à relação entre sujeito e objeto, pautada em códigos culturais sobre o belo e o feio. No caso da sociedade brasileira, "o padrão [de beleza] ideal é branco, mas o real é negro e mestiço" (Gomes 2011 : 54) e a beleza é uma qualidade mais significativa para mulheres do que para homens. Embora Edmonds (2010: 20) não veja esta hierarquia da beleza como um reflexo simples das hierarquias de status e riqueza, no meu estudo elas estão articuladas estreitamente nos casos em que a ascensão social está presente na trajetória de gestantes brancas. Entre estas, havia uma preferência generalizada por olhos claros, cabelos ondulados (mas não crespos, como os de pessoas negras) e nariz afilado. Um fenótipo mais próximo do europeu simbolizava ascendência social e era assim desejado para os bebês. O fenótipo negro, associado em geral com as camadas sociais inferiores, era nitidamente desvalorizado, ao passo que traços associados ao europeu do norte eram mais desejados. Para aquelas que já vinham de famílias de camadas médias, como Marina e Laura, as características do fenótipo europeu não eram tão importantes, de forma que elas se detiveram em traços menos simbólicos como o formato do queixo ou da sobrancelha. Por sua vez, o crescimento de uma classe média negra nas últimas décadas começa a produzir novos desejos, como o de Simone e de outras gestantes negras que queriam para seus filhos uma pele 
muito escura, nariz arredondado e cabelos crespos (ver também Gomes 2011; Souza 2012).

A beleza desejada para o bebê figura então como um bem "herdado" da família - forma de mostrar continuidade -, ao mesmo tempo em que deve ser única ao filho/a. Se no estudo de Edmonds (2010) a beleza é uma meta a ser conquistada ao longo da vida através de várias formas de intervenção no corpo, para as mulheres estudadas é um legado familiar com o qual começar a vida, que conecta de forma diferenciada as gerações. O bebê esperado aparece, portanto, como um ser cujo desenvolvimento no útero deve ser cuidado, e também por meio do qual as relações de parentesco são atualizadas e projetos de afirmação social - seja em termos de posição social, identidade racial ou étnica - são elaborados. Ao mesmo tempo em que o bebê é cuidadosamente inserido em uma rede de relações previamente existente, por meio dele se projeta uma nova linhagem que é simultaneamente uma nova geração da família e uma afirmação de posições almejadas, em consolidação ou já estabelecidas.

\section{BIBLIOGRAFIA}

CANNELL, Fenella, 2011 , "English ancestors: the moral possibilities of popular genealogy", Journal of the Royal Anthropological Institute, n. s., 17 (3): 462-480.

CARSTEN, Janet, 2000a, "Introduction: cultures of relatedness", em Janet Carsten (org.), Cultures of Relatedness. Cambridge, Cambridge University Press, 1-37.

CARSTEN, Janet, 2000b, “'Knowing where you've come from': ruptures and continuities of time and kinship in narratives of adoption reunions", Journal of the Royal Anthropological Institute, n.s., 6 (4): 687-703.

CHAZAN, Lilian Krakowski, 2007, “Meio Quilo de Gente!” Um Estudo Antropológico sobre Ultra-Som Obstétrico. Rio de Janeiro, Editora Fiocruz.

CUSSINS, Charis M., 1998, “Quit sniveling, cryo-baby: we'll work out which one's your mama!”, em Robbie Davis-Floyd e Joseph Dumit (orgs.), Cyborg Babies: From Tecnho-Sex to Techno-Tots. Londres, Routledge, 40-66.

DELILLE, Gérard, 2013, "The shed blood of Christ: from blood as metaphor to blood as bearer of identity”, em Christopher H. Johnson et al. (orgs.), Blood \& Kinship: Matter for Metaphor from Ancient Rome to the Present. Nova Iorque, Berghahn Books, 125-143.

DUARTE, Luiz Fernando Dias, e Edlaine de Campos GOMES, 2008, Três Famílias: Identidades e Trajetórias Transgeracionais nas Classes Populares. Rio de Janeiro, FGV/Finep/CNPq.

EDMONDS, Alexander, 2010, Pretty Modern: Beauty, Sex, and Plastic Surgery in Brazil. Durham e Londres, Duke University Press.

EDMONDS, Alexander, 2012, "A right to beauty", Anthropology Now, disponível em $<$ http://anthronow.com/print/alex-edmonds-a-right-to-beauty > (última consulta em maio de 2016). 
ESSNER, Cornelia, 2013, "Nazi anti-Semitism and the question of 'Jewish blood'", em Christopher H. Johnson et al. (orgs.), Blood and Kinship: Matter for Metaphor from Ancient Rome to the Present. Nova Iorque, Berghahn Books, 227-243.

FERNANDES, Florestan, 1965, A Integração do Negro na Sociedade de Classes. São Paulo, Dominus/Edusp.

FONSECA, Claudia, 2004, "A certeza que pariu a dúvida: paternidade e DNA", Estudos Feministas, 12 (2): 13-34.

FONSECA, Claudia, 2007, "Apresentação - de família, reprodução e parentesco: algumas reconsiderações", Cadernos Pagu, 29: 9-35.

FREYRE, Gilberto, 1981, Casa Grande \& Senzala. Rio de Janeiro, José Olympio (21. a edição). FRY, Peter, 2005, A Persistência da Raça: Ensaios Antropológicos sobre o Brasil e a África Austral. Rio de Janeiro, Civilização Brasileira.

GOMES, Nilma Lino, 201 1, "Movimento negro, saberes e a tensão regulação-emancipação do corpo e da corporeidade negra", Contemporânea, 2: 37-60.

GOW, Peter, 1997, "O parentesco piro como consciência humana”, Mana, 3 (2): 39-65.

HASEnBAlG, Carlos, 1979, Discriminação e Desigualdades Raciais no Brasil. Rio de Janeiro, Graal.

HOLANDA, Sérgio Buarque de, 1982, Raizes do Brasil. Rio de Janeiro, Livraria José Olympio (15. ${ }^{a}$ edição).

HOLY, Ladislav, 1996, Anthropological Perspectives on Kinship. Londres, Pluto Press.

IVRY, Tsipy, 2010, Embodying Culture: Pregnancy in Japan and Israel. New Brunswick e Londres, Rutgers University Press.

JOHNSON, Christopher H., et al. (orgs.), 2013, Blood and Kinship: Matter for Metaphor from Ancient Rome to the Present. Nova Iorque, Berghahn Books.

LUNA, Naara, 2002, "Maternidade desnaturada: uma análise da barriga de aluguel e da doação de óvulos”, Cadernos Pagu, 19: 233-278.

MAGGIE, Yvonne, 1992, “Aqueles a quem foi negada a cor do dia': as categorias de cor e raça na cultura brasileira”, apresentado no Seminário Internacional sobre Racismo e Relações Raciais nos Países da Diáspora Africana, Rio de Janeiro, Centro de Estudos Afro-Asiáticos.

MAYBLIN, Maya, 2011 , "The madness of mothers: Agape love and the maternal myth in Northeast Brazil”, American Anthropologist, 114 (2): 240-252.

McCAlluM, Cecilia, e Vania BUSTAMANTE, 2012, "Parentesco, gênero e individuação no cotidiano da casa em um bairro popular de Salvador da Bahia”, Etnográfica, 16 (2): 221 $-246$.

MORGAN, Lynn, 1997, "Imagining the unborn in the Ecuadorean Andes", Feminist Studies, 23 (2): 323-350.

MOTTA, Flavia Mattos, 2007, “'Em nome do pai e em nome da mãe’: gênero e significado no estudo dos nomes”, em João de Pina-Cabral e Susana de Matos Viegas (orgs.), Nomes: Gênero, Etnicidade e Família. Coimbra, Almedina, 121-143.

NOGUEIRA, Oracy, 1985, "Preconceito racial de marca e preconceito racial de origem", em Oracy Nogueira, Tanto Preto quanto Branco. São Paulo, T. Queirós, 67-93.

NORDQVIST, Petra, 2010, "Out of sight, out of mind: family resemblances in lesbian donor conception”, Sociology, 44 (6): 1128-1144.

PEIXOTO, Clarice Ehlers, e Vincenzo CICCHELLI, 2000, “Sociologia e antropologia da vida privada na Europa e no Brasil: os paradoxos da mudança”, em Clarice Ehlers Peixoto, 
François de Singly e Vincenzo Cicchelli (orgs.), Família e Individualização. Rio de Janeiro, FGV Editora, 7-11.

PINA-CABRAL, João de, 2010, “The truth of personal names", Journal of the Royal Anthropological Institute, 16: 297-312.

PINA-CABRAL, João de, 2013, "The core of affects: namer and named in Bahia (Brazil)", Journal of the Royal Anthropological Institute, 19: 75-101.

RADCLIFFE-BROWN, A. R., 2013, “Estudos dos sistemas de parentesco”, em A. R. Radcliffe-Brown. Estrutura e Função na Sociedade Primitiva. Petrópolis, Vozes, 49-84.

REZENDE, Claudia Barcellos, 2012, "Em torno da ansiedade: subjetividade, mudança e gravidez", Interseções, 14 (2): 438-454.

REZENDE, Claudia Barcellos, 2015, "Nomes que (des)conectam: gravidez e parentesco no Rio de Janeiro", Mana, 21 (3): 587-607.

RODRIGUeS, Nina, 1983, As Raças Humanas e a Responsabilidade Penal no Brasil. São Paulo, Companhia Editora Nacional (3. ${ }^{\text {a }}$ edição).

ROMERO, Sylvio, 1949, História da Literatura Brasileira. Rio de Janeiro, Livraria José Olympio ( $4 .^{\text {a }}$ edição).

SABEAN, David Warren, 2013, "Descent and alliance: cultural meanings of blood in the Baroque", em Christopher H. Johnson et al. (orgs.), Blood and Kinship: Matter for Metaphor from Ancient Rome to the Present. Nova Iorque, Berghahn Books, 144-174.

SAHLINS, Marshall, 2011 , "What kinship is" (part one), Journal of the Royal Anthropological Institute, 17: 2-19.

SCHNEIDER, David, 1980, American Kinship: A Cultural Account. Chicago, The University of Chicago Press (2. ${ }^{\mathrm{a}}$ edição).

SOUZA, Guilherme Nogueira de, 2012, "Negros nas camadas médias e os dilemas da ascensão: identidades e trajetórias na região metropolitana do Rio de Janeiro". Rio de Janeiro, Programa de Pós-Gradução em Ciências Sociais, UERJ, tese de doutorado.

STRATHERN, Marilyn, 1992, After Nature: English Kinship in the Late Twentieth Century. Cambridge, Cambridge University Press.

TAYLOR, J.S., 1998, "Images of contradiction: obstetrical ultrasound in American culture", em Sarah Franklin e Helena Ragoné (orgs.), Reproducing Reproduction: Kinship, Power, and Technological Innovation. Filadélfia, University of Philadelphia Press, 15-45.

VIEGAS, Susana de Matos, 2007, Terra Calada: Os Tupinambás na Mata Atlântica do Sul da Bahia. Rio de Janeiro, 7 Letras.

VILAÇA, Aparecida, 2002, "Making kin out of others in Amazonia", Journal of the Royal Anthropological Institute, 8: 347-365.

WAGLEY, Charles (org.), 1952, Race and Class in Rural Brazil. Paris, UNESCO. 